\title{
Os esquecidos, de Luis Buñuel: o exílio republicano espanhol e a revitalização do cinema social em Latinoamérica*
}

Texto escrito de acordo com a ontografia portuguesa.

$\frac{\text { Manuel Palacio e Jaun Carlos Ibañez }}{\text { Universidad Carlos III/Madrid }}$ 


\section{Resumen}

Los olvidados, primera película que Luis Buñuel aborda en el exilio tras diecisiete años de trabajos propagandísticos o comerciales, es tomada a menudo como un filme representativo del cine mexicano. Una reflexión de conjunto sobre las ideas que gravitan en la vida intelectual del exilio republicano español, sin embargo, nos permite abordar cómo se cruzan en el film tres operaciones esenciales: una estética (el cine como instrumento de poesía), otra ideológica (la crítica por la izquierda del neorrealismo) y una cultural, en la que la imagen de México, relacionada con el drama de España y su tradición cultural, se convierte en el punto de arranque del nuevo cine social latinoamericano.

\section{Palabras clave}

cinema, Los olvidados, Luis Buñuel

\section{Abstract}

Los olvidados, the first film art that Buñuel would embark in_exile after seventeen years of propaganda and commercials, is often taken as a film that represented Mexican cinema. Some thought about ideas that gravitate around the intellectual life of republican Spaniards in the exile, however, makes three far reaching strategies clear: one artistic (the film as an instrument of poetry), one ideological (a critique of the Neorealist movement), and one cultural (a starting point of the new Latin American social cinema), which presented an image of Mexico that related to the tragedy of the Spanish Civil War and its cultural tradition.

\section{Key words}

cinema, Los olvidados, Luis Buñuel 
Perdidos, iay perdidos! los niños de la luz por las rotas ciudades donde las albas lentas tienen sabor a muerto y los perros sin amo ladran a las ruinas...

Rafae] Alberti (1940)

. si la madre España cae, -digo, es un decir-, salid, niños del mundo, id a buscarla!..

César Vallejo (1937)

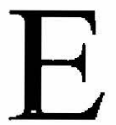

m 1994, próxima já a comemoração do centenário do cinematógrafo, a revista mexicana Somos convocou um escolhido grupo de críticos, historiadores e profissionais -entre os que se encontravam Jorge Ayala Blanco, Nelson Carro, Carlos Monsivais, Tomás Pérez Turrent, Eduardo de la Vega Alfaro, Gustavo García ou Gabriel Figueroa, por citarmos alguns nomespara que elegessem os cem melhores filmes da história do cinema mexicano. Vámonos con Pancho Villa (1935), de Fernando de Fuentes, ocupou o primeiro posto na lista. O segundo lugar correspondia a Los Olvidados (Os esquecidos, 1950). Além das reflexões ou valorações que possa sugerir-nos o hábito contemporâneo dos rankings ou de mecanismos similares de aminoración selectiva $^{I}$-em palavras do poeta Pedro Salinas-, poderia afirmar-se que $O s$ esquecidos chega aos nossos dias em qualidade de obramestra, em magnífica disposição para ser considerada um dos trabalhos mais acabados da história do cinema mexicano. Mas, até alcançar tão altos cumes de prestígio, o filme, porém, teria de realizar um acidentado périplo, já que a sua acolhida inicial não foi tão favorável como poderia deduzir-se da leitura da lista publicada por Somos. O filme era tão duro e inovador, tão crítico e arriscado nos seus

1. Minoração selectiva. 
delineamentos, que, nas suas primeiras exibições, os espectadores reagiram com indignação perante os pretensos sinais de mexicanidade activados por Luis Buñel. Os esquecidos atrevia-se a abordar o problema da delinquência infantil e juvenil nos bairros mais humildes da Cidade de México, e fazia-o recorrendo, como nunca antes se fizera no cinema latino-americano, à verosimilhança do relato.

Buñuel não hesitou em desenvolver três importantes operações: uma estética, que assegurasse a renovação da expressão cinematográfica (o cinema como instrumento de poesia), uma ideológica e política, que outorgasse ao argumento um corpo de denúncia social estritamente revolucionário (a crítica desde a esquerda do neorrealismo, tal e como fizeram os surrealistas nos anos trinta com o realismo social proveniente da União Soviética), e uma cultura] que permitisse encaixar ambas as pretensões na emergência de novos processos de identificação (a consecução de um filme que injectasse os valores da cultura ocidental nos moldes tradicionais da América emergente). $O$ seu acerto na integração dos objectivos descritos explica as razões da privilegiada posição que corresponde a Os esquecidos na história da cinematografia e da enorme influência do seu imaginário no cinema social que se poria em andamento em Latinoamérica desde meados dos anos cinquenta. Vamos ver de que maneira se vincula o verosímil com o poético na proposta de um novo conceito de identidade.

No final dos títulos de crédito iniciais de Os esquecidos pode ler-se o seguinte rótulo: Esta película está basada integramente en hechos de la vida real y todos sus personajes son auténticos ${ }^{2}$. A seguir, os nomes das instituições públicas e dos especialistas que têm contribuido a perfilar a credibilidade do que se vai contar. A intenção de advertir ao espectador sobre esta questão não termina aqui, mas continua no prólogo documental que dá começo ao filme. Enquanto desfilam perante os nossos olhos os sumptuosos e magníficos edifícios de Nova Iorque, Paris e Londres, uma voz em off informa-nos da existência nestas cidades de lares miseráveis, que albergan niños malnutridos, sin higiene, sin escuela, semilleros de

2. "Este filme está baseado integramente em factos da vida real e todas as suas personagens são autênticas". 
futuros delincuentes ${ }^{3}$. A cidade de México, conclui o narrador, no es excepción a esta regla universal ${ }^{4}$. Assim fica esboçado o quadro da ficção, que se inicia com o retorno do cruel Jaibo às suas funções de líder da malta, recém-fugado dum reformatório.

Todos os miúdos e rapazes do grupo rondam a miséria e sofrem um terríbel sentimento de abandono, mistura de orfandade paterna e desatenção maternal. Quando aparece, timidamente, a figura paterna, a mesma que abandonou o Pedro ou o Ojitos, fá-lo em condição de absoluta decrepitude: o pusilânime avô da Meche ou o pai alcoólico do Julián são boa amostra disto. As mães, embora presentes, quase não podem atender os filhos. A mãe do Pedro, longe de tentar interpretar os gestos da sua rebeldia, despreza-o sem compaixão, em nome dos princípios da moral. A da Meche permanece postrada numa cama. No meio deste inferno rapidamente surgirá a tragédia: o Jaibo serve-se do Pedro para dar escarmento ao Julián, a quem acusa de tê-lo delatado. $O$ assassínio deste a mãos do Jaibo faz com que o Pedro reflexione sobre o seu destino. Mas o despiedado delinquente mutilará qualquer alternativa. Na primeira ocasião, provoca o seu ingresso num centro de reeducação infantil. Mais tarde, quando o director do reformatório submete o Pedro a prova, o Jaibo arrebata-lhe o dinheiro que lhe entregaram, submindo-o na desesperação.

Perante as humilhações e a sova que recebe do seu antigo chefe de malta, quando tenta pedir satisfações, o Pedro vinga-se acusando-o em público de assassinato. À noite, o Jaibo vai ao encontro do Pedro no curral da Meche e, aos paus, dá cabo da vida do menino, tal e como fizera com o Julián. Afinal, graças ao aviso de um velho cego ruim, uma das suas muitas vítimas, a polícia cerca o Jaibo e abate-o aos tiros no seu intento de fugida. Sobre o primeiro plano do seu rosto agonizante vemos imagens do seu delírio e ouvimos o seu diálogo com a voz da mãe imaginária e ausente: $i$ Estoy solo, solo! -Como siempre, mi hijito, como siempre. Ahora duérmase y no piense. Duérmase, mi'hijito, duérmase!".

3. que albergam crianças desnutridas, sem higiene, sem escola, viveiros de futuros delinquentes.

4. não é excepção a esta regra universal.

5. Estou sozinho, sozinho! - Como sempre, meu filho, como sempre. Agora durme 
A crueldade do filme provocou as iras dalguns integrantes da própria equipa de filmagem, inclusivamente as do dialoguista Jesús Camacho, Pedro de Urdimalas, que preferiu não ser citado nos títulos de crédito de um filme que, na sua opinião, era enganoso e "miserável". Trás a estreia, influentes personalidades da vida cinematográfica e intelectual mexicana acusaram Buñuel de trair o país que o acolhera, de apresentar uma falsa imagem de México. O filme somente resistiu quatro dias nos ecrãs da capital. Quando tudo indicava que ia repetir-se o caso de Tierra $\sin p a n^{6}$, que $O_{S}$ esquecidos corria o risco de se converter noutra obra maldita de Buñuel, alguns dos seus fieis entusiastas, como Octavio-Paz, conseguem levá-la a concurso no Festival de Cannes. Luis Buñuel voltará a fascinar na França vinte anos depois da apresentação em sociedade de La edad de oro (1930). O seu espectacular triunfo europeu contribuiu a acalmar os ânimos e a diluir, aliás, muitos e arraigados preconceitos no México, onde o público começou a ver com outros olhos os achados narrativos e estéticos do cineasta aragonês. Os esquecidos começava a ser reconhecido, por fim, como algo muito próximo.

Estas considerações sobre o facto de que Os esquecidos primeiro filme "de autor" que Buñuel abordaria no exílio trás dezassete anos de trabalhos propagandísticos ou comerciais- seja tomado como um filme representativo do cinema mexicano, de que seja valorada a sua genuína mexicanidade, não vieram acompanhadas, infelizmente, de uma reflexão de conjunto sobre algumas ideias que gravitam na vida intelectual do exílio republicano. Noutras palavras: como explicarmos que uma obra tão mexicana seja posta em movimento por uma equipa de espanhois (Luis Buñuel, Max Aub, Juan Larrea, Luis Gustavo Pittaluga, Luis Alcoriza) que conservam e exibem uma altíssima consciência de sê-lo e de sentilo, por um grupo de criadores adscritos ao recém-inaugurado exílio republicano espanhol ("transterrados", como os denominaria e se autodenominaria o filósofo José Gaos)? Para respondermos esta

e nāo penses. Durme, meu fitho, durme!

6. Las Hurdes o Tierra sin pan.

7. L'age d'or. 
pergunta quiçá seja conveniente repassar os pormenores que rodearam a concepção do filme.

Naquela altura, nos últimos anos da década de quarenta, o poeta e ensaísta espanhol Juan Larrea e Luis Buñuel reuniam-se quase todos os domingos para conversarem e intercambiarem impressões. Nessas tertúlias frutificariam trabalhos de enorme influência para a obra posterior do cineasta aragonês, como o roteiro Ilegible hijo de flauta, sobre um antigo romance que Larrea escrevera em 1927. Até tal ponto, como indica Victor Fuentes, que temas e ideas visuales del guión y el aliento que animaba las palabras de su introducción sí pasaron a las peliculas mexicanas de Buñuel, con un inconfundible cuño suyo, pero además encarnadas en realidades de la vida y la cultura mexicana ${ }^{8}$. Podemos decir, remata Fuentes, que Os esquecidos, en su concepción profunda, es el Ilegible... mexicanizado, o que, en el trayecto que recorrió del guión de llegible... a la realización de $O_{s}$ esquecidos, Buñuel descubrió la veta de su cinematografia mexicana, en la que ahondaría desde este filme a Simón del desierto, pasando por sus grandes logros de $E l$, Nazarín y $\mathrm{E} 1$ ánge] exterminador?.

Quando e como se iniciou Buñuel nesta senda?. Me sentía tan poco atraído por América Latina que siempre decia a mis amigos: 'Si desaparezco, buscadme en cualquier parte, menos alli' Assim começa o cineasta aragonês o capítulo das memórias dedicadas ao México. Não exagerava. Tudo indica, com efeito, que o translado a este país tem menos a ver com as suas afinidades prévias com Latinoamérica do que com uma situação económica insustentável. Desde 1943, Buñuel vinha sendo objecto de graves denúncias, vilmente atraiçoado por pessoas que conheciam de perto as

8. temas e idelas visuais do roteiro e o alento que animava as palavras da sua introduçăo passsaram aos filmes mexicanos de Buñuel com um inconfundibel selo seu, encarnados, alias, em realidades da vida e da culfura mexicana.

9. Podemos dizer que Os esquecidos, na sua concepção profunda, é o llegible... mexicanizado, ou que, no trajecto que percorreu do roteiro de llegible... a reallzação de Os esquecidos, Buñuel descubriu a beta da sua cinematografia mexicana, em que aprofundaria desde este filme a Simāo do deserto, passando pelos seus grandes logros de Nazarin e $\mathrm{O}$ anjo exterminador.

10. Sentia-me tão pouco seduzido pela América Latina que sempre falava para os meus amigos: 'Se desapareço, procurai-me em qualquer parte, menos la'. 
suas actividades políticas; em primeiro lugar pelo pintor Salvadot Dali, mais adiante pelo músico e ex-militar republicano Gustavo Durán. A raiz das delações destes dois antigos amigos, a súa presença na cena pública norte-americana ficaria vetada para sempre. Nesta situação, o cineasta àragonês encontra-se num beco sem saída e predisposto a aceitar as facilidades que se lhe oferecem amavelmente desde o México. Mal chega à capital mexicana prepara o regresso aos estúdios com Gran casino ${ }^{I l}$ (1946), musical produzido' por Oscar Dancigers e protagonizado por Libertad Lamarque e Jorge Negrete. Neste contexto tem lugat o encontro de Buñuel com uma nutrida e culturalmente activa colónia espanhola. É assim, em definitiva, como conclui um prolongado e aziago período de isolamento nos Estados Unidos.

Entre as figuras mais sobressalientes do exílio republicano no México destacava pelo seu enérgico activismo americanista Juan Larrea. A admiração de Buñuel -personagem muito pouco partidária deste tipo de entregas- em relação a Larrea era sólida, antiga e procedia de interesses comuns e diversos. A publicação dalguns poemas de Larrea, gestionada pelo seu amigo Gerardo Diego, bastou para se fazer notar nos círculos literários madrilenos. A sua fama comó poeta chegou a ser extraordinária. Numa das suas viagens à Espanha, César Vallejo descobre com assombro o prestígio de que gozá o seu amigo, e assim o comunica por carta ao próprio Larrea: la élite española tiene por tu obra una admiración, y sobre todo, un respeto casi religioso ${ }^{12}$. Não em vão Buñuel referir-se-á a ele nas suas memórias como uno de los más grandes poetas españoles ${ }^{13}$.

Contudo, a fins dos'ános vinte, trás atravessar uma profunda crise pessoal, Larrea decide abandonar o exercício da poesía. Todo o seu interesse se centra então no ensaio e no estudo da arqueologia e da arte pré-colombiana. Em 1930 translada-se com a sua mulher ao Peru, onde permanecerá áté ao ano seguinte, e ali reune uma valiosa colecção de peças incas que acabará por doar ao governo da

11. Gran Cassino.

12. "a elite espanhola sente pela tua obra uma admiração e, nomeadamente, um respeito quase religioso".

13. "um dos maiores poetas espanhois". 
República. A sublevação franquista surprende-o na França, onde a sua amizade com figuras da altura de José Bergamín, presidente da Aliança de Intelectuais Antifascistas, ou Pablo Picasso, situa-o como uma das personagens determinantes, junto ao próprio Buñuel ou a Max Aub, na promoção de obras e projectos culturais de repercussão internacional em defesa da República. A princípios de 1938 Larrea põe em andamento o Comité de Ajuda aos refugiados espanhóis e a Junta de Cultura Espanhola, onde Louis Aragon e Pablo Neruda colaboram na tarefa de obterem vistos de emigração à América para os intelectuais que se dirigem ao exílio. Recém-chegado ao México, durante 1940, edita a efémera revista España Peregrina, origem do seu seguinte projecto editorial, Cuadernos Americanos. Em 1943 publica Rendición de Espiritu. Um ano mais tarde vê a luz Surrealismo entre viejo y nuevo mundo.

A partir de umha leitura em chave poética da história, e em. particular da história das religiões, Larrea sistematizara nos seus livros e artigos, desde a sua chegada ao continente americano, uma poderosa teoria sobre o lugar simbólico que o México, a Nova Espanha, ocupava na história do homem, e, portanto, da cultura contemporânea universal. Mediante a práxis do humanismo, profetizava Larrea, os homens recuperarão a sua verdadeira razão espiritual de ser, e com isso farão possível a chegada de uma nova Idade de Ouro, a reactualização do paraíso perdido. Influído pelas interpretações teleológicas do pensamento judeu-helenístico-cristão e pelas obras de Rimbaud, Darío, Huidobro e Vallejo, Larrea entende que a história se encaminha a um mundo e um tipo de homem novo, a uma realidade de novo cunho, espiritual, harmónica, livre de desigualdades sociais, cujo advento se anteciparia com o estouro de um cataclismo devastador (a segunda grande guerra).

Alguns acontecimentos relacionados com o Caminho de Santiago, com o culto medieval ao Finis terrae, essência da identidade europeia, ocidental, se configuravam nos argumentos de Larrea como um episódio chave. Máxime quando em 1944 o professor Ramón Martínez López o coloca sobre a pista dos trabalhos que se levaram a cabo para identificar os restos que se veneravam na.catedral compostelana, ençontrados na sua nave central numas escavações de 
finais do século XIX. As pesquisas inclinavam-se pela hipótese de que pertencessem ao herege Prisciliano e aos seus companheiros de martírio. Em posteriores estudos, Larrea definirá Prisciliano como um asceta de devoción exaltada, (que) de en modo alguno intentó la desviación del cristianismo sino su prolongación hasta sus consecuencias naturales que son las del espiritu ${ }^{14}$ (Larrea, 1984, p.142). A sua perseguição e execução por parte da materialista Igreja de Roma, ao serviço das intrigas políticas do século IV, supusera um importante acontecimento no processo de descomposição do humanismo cristão. "De ser cierta la suplantación de Prisciliano por Santiago", afirma Larrea, "su descubrimiento en estos precisos instantes equivaldría a una comprobación efectiva de las tesis troncales de Rendición de Espiritu ${ }^{i 5}$ " (op. cit., p.27).

Com efeito: o reino da Pomba (Jesuscristo-Juan) triunfaria finalmente sobre o da Espada (Igreja-Pedro). No sacrificio da guerra e na posterior diáspora espanhola (Santiago-Finisterra) encontrar-se-ia o gérmen de "a apocalíptica Nova Jerusalém" (Méxicocontinente americano). Assim explica as consequências finais dos seus pressupostos o próprio Larrea, que assume o papel de profeta do nosso tempo e desvela a importância histórica do continente americano, especialmente do México, "a apocalíptica Nova Jerusalém", como cenário definitivo da futura redenção:

De tal esquema se deduce que si, dentro de los conceptos metafisicos de nuestra tradición cultural, habia existido un mundo del Padre, asociado geográficamente al Asia, y se venia viviendo el mundo mediterráneo del Hijo, propio de Europa, al final de éste, en el Finisterre, debia entrar en actividad el sacrificio de la sangre para transferirse al celeste $y$ paradisiaco mundo verbal del Espiritu, el cual, señalado por

14. asceta de devoção exaltada, (que) de maneira nenhuma tentou a desviação đo cristianismo, mas a sua prolongação até as suas consequências naturais que săo as do esplrito.

15. De ser verdadeira a suplantação de Prisciliano por Santiago, o seu descobrimento nestes precisos instantes seria equivalente a uma comprovaçăo efectiva das teses fundamentais de Rendición de Espiritu. 
Santiago de Galicia, se ubicaba en América. Este era, en un lenguaje superior, de orden objetivo cultural, el sentido sobrehumano de nuestra época, su transmisión del subconsciente cósmico al consciente colectivo ${ }^{16}$. (op. cit.: 23)

Ao tempo, Prisciliano emerge da figura do mito de Santiago com o fim de revelar na consciência colectiva esta experiência de transfiguração. No artigo "Introducción a un Nuevo Mundo", publicado no primeiro número da revista España Peregrina (1940), já se puderam ler, expostas com irrepreensível nitidez, algumas das vigorosas conviç̧ões de Larrea que atrairam a atenção de Buñuel e doutros eminentes intelectuais do exílio:

$3^{a}$. El acento creador del mundo nuevo que se anuncia gravita geográficamente sobre el continente americano o continente del espiritu, llamado a equilibrar a los otros dos grandes bloques continentales del mundo antiguo: Asia-Oceania y Europa-Africa.

4". Corresponde a España, al pueblo español, inmolado, facilitar, rindiendo su Verdad, el acceso a ese mundo de civilización verdadera, ser su precursor efectivo e indispensable ${ }^{17}$. (Larrea, 1940)

16. De tal esquema deduz-se que se, dentro dos conceitos metafisicos da nassa tradição cultural, existira um mundo do Pai, associado geograficamente à Ásia, e se vinha vivendo o mundo mediterrâneo do Filho, proprio da Europa, no final deste, na Finisterra, devia entrar em actividade o sacrificio do sangue para se fransferir ao celeste e paradisiaco mundo verbal do Espírito, que, assinalado por Santiago da Galiza, se localizava na América. Este era, numa linguagem superior, de ordem objectivo cultural, o sentido sobrehumano da nossa época, a sua transmissão do subconsciente cósmico ao consciente colectivo.

17. $3^{\approx}$. $O$ acenfo criador do mundo novo que se anuncia gravita geograficamente sobre o continente americano ou continente do espirito, chamado a equilibrar os outros dois grandes blocos continentais do mundo antigo: Asia-Oceania e Europa-África.

4. Corresponde a Espanha, ao povo espanhol, imolado, facilitar, rendindo a sua Verdade, a aceso a esse mundo de civilizaçăo verdadeira, ser o seu precursor efectivo e indispensável. 
Não é este o lugar, como pode intuir facilmente o leitor, para estendermo-nos na vida e na obra de Larrea. Bastará com indicar de que maneira a sua presença próxima de Buñuel, nos seus primeros quatro anos de residêncià no México, incidiria não só no pensamento e na obra posterior do cineasta aragonês; mas também, e de maneira determinante, na mudança da sua atitude quanto ao ser e ao acontecer, nos seus infinitos matizes, da complexa e fascinante realidade mexicana.

Tamisados os seus alentos místico-proféticos, as imagens e os lemas defendidos por Larrea chegaram a ser muito influentes no pensamento do exílio republicano espanhol (pensemos em José Bergamín, León Felipe ou Emilio Prados), assim como em destacados poetas latino-americanos que viveram de perto a tragédia espanhola, como Octavio Paz ou Pablo Neruda. Uma influência à que será especialmente propenso Buñuel. A partir do contacto com Larrea, o conceito de religião converte-se em algo mais complexo do que uma simples estratégia de dominação por parte dos poderosos. Ao mesmo tempo, o cineasta convence-se rapidamente de estar imerso numa sociedade complexa, de enorme riqueza cultural, capaz de converter as suas contradições num prometedor cenário de renovação ideológica e política, e de projectá-lo com força para o resto de Latinoamérica e do mundo.

O México deixa de ser o país do folclore e das revoluções pitorescas, condenadas ao fracasso em função da sua natureza populista -tal e como se evoca na sequência inicial de Ensayo de un crimen $^{18}$ (1955)-, e transforma-se num espaço mítico, em que podem encarnar-se as eternas personagens de Cervantes, Calderón ou Galdós. Algunas de las películas de Luis Buñuel -La edad de oro, Os esquecidos-, sin dejar de ser cine", escreve Octavio Paz, nos acercan a otras comarcas del espíritu: ciertos grabados de Goya, algún poiema de Quevedo o Péret, un pasaje de Sade, un esperpento de.Valle Inclán, una página de Gómez de la Serna... Estas películas pueden ser gustadas y juzgadas como cine y asimismo como algo perteneciente al universo más ancho y libre de esas obras, preciosas

18. Ensayo de un crimen.

Significação $22 \cdot 142$ 
entre todas, que tienen por objeto tanto revelarnos la realidad humana como mostrar una vía para sobrepasarla ${ }^{19}$. (Paz, 1974)

A imagem do México e dos mecanismos imaginativos de reflexão sugeridos por Larrea conectavam com o espírito visionário da vanguarda, tão querido por Buñuel, e estabeleciam uma adequada plataforma de distanciamento a respeito do formalismo costumista, então hegemónico, cujas origens podiam rastrear-se na pintura mural de Rivera, Orozco e Siqueiros, ou nos trabalhos fotográficos de Edward Weston, Tina Modotti ou Manuel Álvarez Bravo, presente na filmagem do não concluido ;Que viva México! (1933) e mestre do operador Gabriel Figueroa. Inspirando-se em Vallejo, Larrea apresentava uma imagem do México relacionada com o drama da Espanha e a sua tradição cultural que se afastava dos lugares comuns e dos estereótipos de costume, tão desprezados por Buf̃uel (siento un profundo horror hacia los sombreros mexicanos ${ }^{20}$ ). Isto é: não se trata tanto de procurarmos a correspondência das imagens entre um e otro autor, quanto de compreendermos como a cosmovisão de Larrea se vai converter na chave mestra que facilita o acesso a um território intelectual e cultural até esse momento ignorado pelo cineasta, que lhe permitiria a articulação de novos sinais de identidade sobre o povo mexicano -e por extensão, sobre toda Latinoamérica-, mais conectados com o seu tempo social e político do que os tradicionais, convencionais naquela altura, que se mantinham como herança de uma época em processo de desaparição.

Mas voltemos à génese de $O s$ esquecidos e às reuniões entre Larrea e Buñuel. Estábamos pasando por entonces una época muy mala, lembra daquele tempo o cineasta aragonês; Bueno, Larrea sobre todo, yo todavia tenía alguna reserva de $\mathrm{El}$ gran calavera (1949). Nos reíamos mucho. Más de lo que él dice. Él estaba dispuesto a lo

19. Alguns dos filmes de Luis Buñuel-L'age d'or, Os esquecidos-, sem deixarem de ser cinema, nos aproximam a outras comarcas do espirito: certas gravuras de Goya, algum poema de Quevedo o Péret, uma passagem de Sade, um esperpento de Valle Inclán, uma página de Gómez de la Serna... Estes filmes podem ser desfrutados e julgados como cinema e também como algo pertencente ao universo mais largo e livre dessas obras, preciosas entre todas, que têm por objecto tanto revelarem-nos a realidade humana quanto mostrarem-nos uma via para sobrepassá-la.

20. sinto um profundo horror aos chapéus mexicanos. 
que fuera con tal de ganar dinero, y... se nos ocurrió hacer un melodrama de lo peor, acerca de un papelerito: Su huerfanito, jefe. Nos divertiamos acumulando elementos, uno peor que el otro, una serie de plagios, tomando de aquí y de allá, como si fuese una pelicula de Peter Lorre ${ }^{21}$ (Aub, 1984, p.118)

$O$ sucesso de bilhetaria de $E l$ gran calavera ${ }^{22}$, o segundo filme dirigido no México por Luis Buñuel, leva o produtor Oscar Dacingers a cumprir uma antiga promessa: a produção de um filme com pretensões estéticas, uma produção "de qualidade", ou se se prefere, "de autor", com que o cineasta aragonês pudesse actualizar o génio cinematográfico que demonstrara em Un perro andaluz ${ }^{23}$ (1929), La Edad de Oro (1930) ou Tierra sin pan (1933). Buñuel, que já vira como Dancigers rejeitara o experimentalismo de llegible hijo de flauta, propõe-lhe algo aparentemente mais comercial, $; M i$ huerfanito, jefe!, a história de um miúdo pobre, cauteleiro, que logra virar rico graças a um inverosímil golpe de fortuna: o último número que, apesar dos seus esforços, não conseguiu vender recebe o primeiro prémio.

Costuma resolver-se em poucas linhas a anedota de que o argumento parece tão inadequado a Dancigers que este sugere a Buñuel a possibilidade de escrever "algo mais sério" sobre as crianças pobres da Cidade de México. $\mathrm{O}$ próprio cineasta atribui-lhe a ideia germinal de $O s$ esquecidos numa entrevista com Tomás Pérez e Tomás de la Colina: "Lo propuse ("¡Mi huerfanito, jefe!") a Dancigers... No está mal-me dijo Dancigers-, pero es un folletoncito. Mejor hagamos algo más serio. Una historia sobre los niños pobres de México ${ }^{24 "}$ (Pérez y De la Colina, 1993: 49). Se descontamos o

21. "Estávamos a passar uma época péssima. Bom, Larrea sobretudo; eu ainda tinha alguma reserva de El gran calavera (1949). Ríamos muito. Mais do que ele diz. Ele estava prestes a fazer o que for para ganhar dinheiro, e... ocurriu-se-nos fazer um melodrama péssimo, sobre um cauteleirinho: Su huerfanito, jefe. Divertiamo-nos acumulando elementos, cada um pior do que o anterior, uma série de plágios, tomando de cá e de lá, como se fosse um filme de Peter Lorre".

22. El gran calavera.

23. Um cäo andaluz.

24. "Propu-lo ("iMi huerfanito, jefe!") a Dancigers... Nāo está mal, mas é um folhetimzito. E melhor fazermos algo mais sério. Uma história sobre as crianças pobres do México". 
grosso verniz de ironia e autocrítica com que, em ocasiōes, se fustiga Buñuel, não seria despropositado aventurar que talvez o produtor se limitasse a assinalar a possibilidade de que uma estrutura dramática, sem equívocos, seria melhor recebida pelo grande público do que uma operação burlesca e anti-sentimental sobre a transgressão do género melodramático. Para Dancigers, a opção exclusiva do drama infantil habitual, insistindo no argumento já esboçado da pobreza, isto é, configurando-se como drama social, reduziria os riscos nos circuitos nacionais e internacionais de exibição, e talvez tivesse um aceitável rendimento de bilhetaria, a julgar pela boa recepção que dispensavam os espectadores de todo o mundo ao neorrealismo italiano.

Tal observação, própria de um produtor avezado na interacção entre o cinema e o seu público, como era, por outra parte, o próprio Buñuel, disparou mecanismos de criação alternativos, e obrigou o cineasta aragonês a reflectir sobre a relevância da oportunidade que se lhe estava a brindar. Com efeito, por que não se arriscar a insertar a capacidade transgresora do cinema de vanguarda nos cauces convencionais da ficção? Os projectos de adaptação dos romances Cumbres borrascosas ${ }^{25}$ ou Las cuevas del Vaticano, na primeira metade dos trinta, constituiram um primeiro intento de encarar este desafio cinematográfico. Anos mais tarde, durante o seu périplo norteamericano, mais afastado de posiçōes artísticas ou Jiterárias, desenvolveu sem sucesso algumas ideias para a indústria de Hollywood: bosquejos de gags, cenas e inclusive argumentos completos, como La novia de medianoche, em colaboração com o professor de literatura e escritor galego José Rubia Barcia, roteiro de mistério e suspense que, aliás, Antonio Simón rodaria na Galiza de 1997. "¿Esa vuelta a ti mismo con Os esquecidos", chegaria a perguntar Max Aub a Buñuel, "fue un poco por casualidad o porque la buscaste desde que llegaste a México? No, no. No buscaba nada, respondeu o cineasta. Me parecía imposible. Crei que no volvería a hacer cine personal. Creí que habia terminado ${ }^{26}$. (Aub, op. cit., p.119)

25. O morro dos ventos uivantes ou Wuthering heights.

26. Essa volta a ti proprio com Os esquecidos foi um pouco por acaso ou porque o procuraste desde que chegaste ao México? Năo, nãa. Não procurava nada. 
Se bem é verdade que Buñuel não buscara deliberadamente o projecto que conduziria a Os esquecidos, temos de descartar, por outro lado, que o filme se articulasse por acaso. Ao voltar sobre a sugestão de Dancigers, à sua vez baseada na figura inicial de um coitado miúdo cauteleiro, o cineasta apercebeu-se de que as circunstâncias o convidavam não tanto a abordar a ficção a partir da literatura, mas a partir do simples registro da vida; desde um género, o documental, que tão impecavelmente chegara a dominar graças à sua dupla trajectória de cineasta e de supervisor de documentários de propaganda, primeiro ao serviço da embaixada republicana espanhola em Paris, e depois no Museu de Arte Moderna de Nova Iorque. À luz da proposta de Dancigers, a nova ideia, convertida já no projecto de Os esquecidos, transformava-se assim, à vez que em desafio fascinante, num dos acontecimentos mais destacados da carreira profissional de Luis Buñuel.

Parecia-me impossivel. Achei que não voltaria a fazer cinema pessoal. Achej que tinha terminado. 


\section{Bibliografia}

AUB, M. 1944. Conversaciones con Luis Buñuel. Madrid: Aguilar. BUÑUEL, L. 1982 [8 ${ }^{\mathrm{a}}$ ed. 1997]). Mi último suspiro. Barcelona: Plaza y Janés.

LARREA, J. 1984. Poesia. Revista ilustrada de Información Poéti$c a, n^{\circ} \mathrm{s} 20-21$.

PAZ, O. 1974. Los hijos del limo: del romanticismo a la vanguardia. Barcelona: Seix Barral.

PÉREZ TURRENT, T. y DE LA COLINA, J. 1993. Buñuel por tuñuel. Madrid: Plot. 